\title{
Discussion on how internal audit play its full role for increment of enterprise value
}

\author{
Shuhua Xu \\ Accounting School, Inner Mongolia University of Finance and Economics, Hohhot Inner \\ Mongolia, 010000, China
}

Keywords: Internal audit, Play, Increment of enterprise value.

\begin{abstract}
With the continuous growth of Chinese economy, regarding actual enterprise internal financial management measures, relevant management mechanism has kept upgrading and the developmental trend is tending to be more international. How to stand firm in the competitive market, enterprise should not only improve its own market competitiveness, but also should make effective upgrading and intensification on internal financial management measures to guarantee the centralized handling of relevant issues and to use corresponding measurement governance strength for complete establishment and optimized operation on the internal control structure. This article makes brief analysis on the definition of internal audit and relevant institution standard, and then analyzes the connotation and measuring datum of enterprise value, and finally specifically discusses detailed influential effect on increment of enterprise value from internal audit for the purpose of providing effective financial advice for relevant management staffs for reference.
\end{abstract}

\section{Definition of internal audit and institution standard}

\section{Definition of internal audit}

Since the release of "Standards for the Professional Practice of Internal Auditing of The Institute of Internal Auditor" in 1978, Chinese internal audit mechanism has gradually become an indispensable management mechanism in enterprise from the initial evaluation activity. During the process of internal audit, relevant inspection items and evaluation mechanism are mainly conducted to make scientific control on enterprise internal financial condition. Enterprise's operating internal audit mechanism during the actual operation process is to help organize relevant departments to implement their own actual duties and to use effective management mechanism for enterprise's overall project management and upgrading. Also, in 2001, IIA has made further explanation and the reform was a time transgressive audit mechanism innovation. In new project regulations, internal audit mechanism has become an independent existence and an objective consulting service for evaluation system with the main target changed into helping increment of enterprise value and using relevant project management mechanism for operation and effective management of enterprises organizational structure $^{[1]}$. In new internal audit mechanism, relevant project analysis mechanism and management measurements are with systemic and standardized, and relevant evaluation methods are with more technical standard. Relevant financial staffs use internal audit mechanism for enterprise effective governance to make sure that enterprise internal control and risk control projects can be effectively handled. Only by guaranteeing the optimized operation of internal audit projects can enterprise's governance structure be upgraded fundamentally to truly achieve the increment of enterprise value.

\section{Institutional standard of internal audit}

With the continuous development of economy and upgrading of enterprise financial management structure, China is paying more and more attention to enterprise internal audit structure. In 2008, "Enterprise Internal control standards" were issued by Ministry of Finance, Auditing Administration, CSRC, CBRC, and China Insurance Regulatory Commission together. Internal audit mechanism has been further introduced to essentially make sure the independence of auditing departments. Through 
the optimization of self auditing and supervision ability, enterprise operation mechanism of self management and control has also been improved ${ }^{[2]}$.

\section{Internal audit functions}

Enterprise internal financial department establishes relevant internal audit mechanism with the most important objective to establish effective project management strategies to realize relevant functions such as supervisory function, consulting function and evaluation function. First is supervisory function. In actual enterprise management process, ownership and managerial authority has also transformed. Enterprise owner entrust the right of management to relevant agent so that he is not familiar with the enterprise overall development condition. Internal audit mechanism is to make centralized management and control on relevant operation mechanism and management condition, and make sure that internal audit mechanism makes effective project supervision on daily financial work during the auditors' upgrading working operation so as to use financial statement for authentic audit and feedback. Second is consulting function. For enterprise development, relevant internal audit mechanism is an effective consulting approach. Enterprise internal audit institutions use relevant measurements to collect and summarize relevant data to satisfy the consulting business in other departments of the enterprise and also provide advice, consulting and coordination work. It is based on the independent structure and its effectiveness of internal audit mechanism that overall consulting advice can be authentic and effective and to make sure that internal audit mechanism can bring more social benefits and values for the enterprise and to some extent to achieve increment of enterprise value. Third is evaluation function. In actual audit project operation process, relevant audit mechanism should effectively deal with enterprise internal institution, business and work flow, and make sure it can provide effectively independent suggestions and conclusions for relevant departs so as to achieve independent and objective evaluation ${ }^{33}$. In addition, internal auditors should complete effective internal audit reports so as to make corresponding evaluation and make sure the reasonable operation of recommendation work.

\section{Introduction of enterprise value connotation}

\section{Enterprise value connotation}

During the evaluation process of enterprise value, there exist different arguments in academic circles and entity enterprises. The academic field evaluates enterprise value from the perspective of financial management. They think that enterprise actual profits and profitability are the embodiments of enterprise values, and use debt paying ability and sustainable development capacity of the enterprise as the standard to evaluate enterprise developmental value and ability. But entity inner-enterprise make relevant structural analysis from the market perspective thinking that enterprise values are mainly reflected in the future expected actual value of enterprise, made up of basic equity capital value and liability value, with the main embodiment form as that the higher share price of enterprise stock after going public is, the self value of enterprise is larger. In a word, enterprise values analyzed from different perspectives are positive to make sure that enterprise development prospect is promising with good expectations ${ }^{[4]}$.

\section{Measuring datum of enterprise value}

During the process when make centralized evaluation on enterprise value, relevant evaluation standards are mainly divided into waiver pricing method, discount cash flow method, EVA appraisal method, and relative appraisal method. In option pricing method, relevant evaluation standard is only applicable for special case for future share option so that relevant price is totally depending on the uncertainty of investing real projects. Since the usage of the cash flow for the regulation of current value will lead to poor applicability of relevant methods. During the operation process of discount cash flow method, the precondition is that the capital market is fully effective to realize effective enterprise expected cash flow discounting and to make sure relevant staffs can use the age limit to 
calculate enterprise value. As relevant numerical values in the calculation can directly reflect enterprise, it is widely applied in enterprise actual operation. Moreover, relevant measurements during the operation process are mainly the application of increment of cash flow and principle of time value.

\section{Impact of internal audit on enterprise value increment}

For enterprise operator, only ensuring relevant issues be effectively solved can the overall financial management work is conducted smoothly. Establish relevant project analysis mechanism so as to achieve the upgrading of overall financial management structure. Relevant staffs should carefully analyze the influence of internal audit on enterprise value increment and actively apply relevant project strategies to achieve the optimization of enterprise governance structure, focus on upgrading the measurements on enterprise environment governance and risk control management mechanism so as to realize the improvement of overall enterprise operation and financial ability.

\section{Improve enterprise management measures}

In actual enterprise inner management, relevant financial staffs should deal with relevant issues based on internal audit mechanism and enterprise management structure. Main management project is to establish relevant cognition of control system in actual project handling mechanism. In authorized project of enterprise management, it is mainly the specific shareholder and relevant entrusted accountability. But in internal audit mechanism, the range of relevant accountability is wide including not only entrust responsibility management in different levels of inner-enterprise but also playing roles on the enterprise actual governance and management ${ }^{[5]}$. Firstly, listed companies can use relevant strategies to effectively reduce the agent costs during the process of actual internal audit project operation, and effectively improve the overall management level of the enterprise to establish effective project handling mechanism and operation strategies. Relevant enterprise financial department uses relevant supervisory mechanism to make effective calculation on enterprise internal financial statement and disclose relevant financial information so as to achieve the optimized operation of overall enterprise financial management mechanism. Secondly, if there is conflict between enterprise internal management staffs with shareholders, relevant internal audit mechanism can ensure to make objective supervisory evaluation on each interest-related department so as to realize the authority and independence of overall internal audit membership management.

In addition, in enterprise internal financial management projects, relevant internal audit mechanism can have effective impact on governance. Since enterprise internal audit departments are independent management departments in enterprise, so the higher degree of membership is, the more independent structured will be. Therefore, to make sure that internal audit projects play positive roles in actual enterprise operation process, it must enter the enterprise governance level. If basic internal audit department subordinated to financial management departments, relevant management conditions and problems will be more so that supervisory strength produced will be limited. If internal audit department is subordinated to the governance level, effective supervision and management on relevant issues can be conducted including board of directors and board of supervisors within enterprise. In this way, through joint supervision from management staffs, enterprise internal financial handling projects can be truly optimized so that relevant projects can be essentially optimized and upgraded.

\section{Improve enterprise internal control}

During researches on internal audit projects, relevant researchers should make centralized handling on the objects in the overall management mechanism and the operation strategies as internal audit uses two models to promote the increment of enterprise value. On one hand, establish effective value-added service to ensure the overall project accords the time requirement to further expand the enterprise developmental profits. On the other hand, during the process of running internal audit mechanism, it can effectively reduce enterprise operation costs and provide effective driving force for 
enterprise development. In actual internal audit mechanism operation, the most important thing for settle down relevant issues is that relevant financial management staffs need operate internal audit projects according practical situation, make comprehensive analysis on enterprise before-middle and after operation activities and make organization and collection of data, make relevant management and supervision to ensure enterprise can reduce operation risks in relevant investment projects.

In addition, during the operation of actual internal audit mechanism, relevant management staffs must guarantee the audit control on enterprise supervision and evaluation system to establish regular and casual internal control effect acceptance inspection so as to make sure relevant mechanism has real efficiency. In the process of internal upgrading project design and operation calculation, relevant staffs can make effective project rectification according to practical situation so as to make sure audit advice can truly positively impact the overall enterprise operation. Besides, in actual project operation mechanism, relevant management staffs should use self-evaluation mechanism to comprehensively promote relevant management measurements to guarantee employees in all levels of the audit project can actively participate. To establish all-staff audit mechanism, more employees should know real internal control measures, and also make sure relevant staffs apply some common knowledge and measurements of audit they have learned into their own work so as to achieve the increment of enterprise value.

\section{Upgrade risk management strategy}

The market is constantly changing. Enterprises only by establishing clear cognition of market and fully understanding relevant market operation can they truly realize the optimization of overall financial management effect. Before running relevant business, relevant financial staffs should make effective estimation on the risk and establish relevant elusion tactics, and ensure enterprise can try as far as possible to reduce relevant operation risk and financial damage. During the enterprise financial project operation process, establish effective risk handling mechanism to make sure enterprise can face up to market risks. Establish effective handling measurement to reduce relevant value losses to improve the possibility and approaches to get value increment. In the late stage of enterprise project operation, make effective analysis a rectification on relevant projects and establish effective project evaluation to realize the effective maintenance of enterprise overall value on the basis of reducing relevant financial risks so as to guarantee the growth of enterprise value.

In real risk management process, relevant management staffs should make optimized management specific on relevant projects. Firstly, make sure internal audit mechanism has effective project supervision on risk management. Use relevant evaluation system to make actual assessment on risk management to specifically improve enterprise ability to cope with risks and financial risks. Secondly, internal audit departments should complete relevant training to provide relevant value-added service for consultants and self-evaluation in the internal control.

\section{Conclusion}

To sum up, during enterprise actual operation, relevant audit staffs should focus on establishing effective management and control measurements on relevant issues to make sure the overall management effect can be optimized reflected. In the process of internal audit project, relevant management staffs should pay attention to effective evaluation and management of risk management, internal control and internal governance projects so as to truly achieve enterprise sustainable development.

\section{References}

[1] Hao Yugui, Gao Mingyang. Internal audit increases the value of high technology enterprises—set DH as the example, Productivity Research, 2015,18(09):150-154. 
[2] Xiao Zhongyun, Yu Haiyun. Influential factors of internal audit increment-empirical test based on structural equation model, Collected Essays on Finance and Economics,2014,17(12):61-68.

[3] Li Tao, Zhao Zhiwei, Jiang Yuanbin. Theoretical framework research on internal audit management system transformation and upgrading in group companies-thinking based on the perspective of value, Modernization of Management,2014,34(04):53-55.

[4] Wang Haibin, Dong Qian. Innovation research on Chinese enterprise internal audit under knowledge-based economy background, Modernization of Management,2015,35(03):43-45.

[5] Wei Qianmei. Research on evaluation index system of internal audit, Social Scientist, 2015,17(05):74-78. 